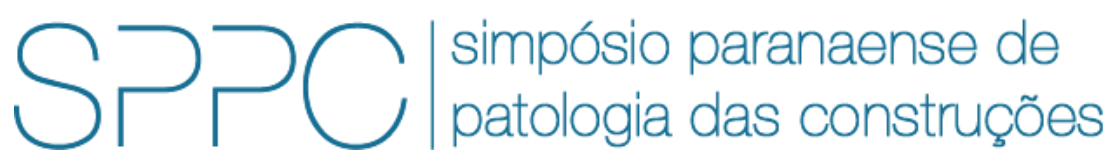

ISSN 2526-7248 artigo 2SPPC1020, pp. 237-252, 2017

\title{
Avaliação não destrutiva do ataque interno por sulfatos em testemunhos de CCR de uma barragem
}

\author{
Hudson Goto1, Betina Lepretti Medeiros², Marcelo Henrique Farias de Medeiros ${ }^{3}$, Mariana O.G.P. \\ Bragança $^{4}$, Kleber Franke Portella ${ }^{5}$, Isabela Cristina de Oliveira ${ }^{6}$, Jeferson Luiz Bronholo ${ }^{7}$ \\ ${ }^{1}$ Engenheiro Civil, Companhia Paranaense de Energia (Copel) - Mestrando (UFPR), \\ hudson.goto@copel.com \\ 2 Engenheira Civil Msc., Institutos Lactec - Doutoranda (UFPR), betina@lactec.org.br \\ 3 Professor Doutor, Departamento de Construção Civil da Universidade Federal do Paraná (UFPR), \\ medeiros.ufpr@gmail.com \\ 4 Professora Doutora, Departamento de Construção Civil da Universidade Federal do Paraná \\ (UFPR)/Institutos Lactec, mariana.portella@lactec.org.br \\ 5 Professor Doutor, Institutos Lactec, portella@latec.org.br \\ ${ }^{6}$ Engenheira Civil Msc., Companhia Paranaense de Energia (Copel), isabela.oliveira@copel.com \\ 7Tecnólogo em Edificações, Institutos Lactec, jeferson.luiz@lactec.org.br
}

Resumo: A presença de íons sulfatos $\left(\mathrm{SO}_{4}^{2-}\right)$ no interior da matriz cimentícia de concretos pode dar origem a um tipo de ataque interno, resultando na sua deterioração ao longo do tempo. Estes íons podem reagir com os álcalis do cimento, formando compostos como a gipsita, etringita e outros sais de sulfato, com características expansivas. Este ataque pode provocar novas reações químicas, alterando as propriedades físicas e mecânicas das estruturas de concreto. Assim, o presente trabalho teve como objetivo avaliar o comportamento físico e mecânico de testemunhos de concreto compactado a rolo (CCR), extraídos de uma barragem de usina hidrelétrica com sinais de manifestação patológica de ataque interno por sulfatos. Após a inspeção visual das estruturas, foram selecionados os locais para a extração dos testemunhos e a realização dos ensaios de resistividade elétrica e resistência à compressão axial. Resultados diferentes foram obtidos no bloco 22, com baixos valores de resistividade elétrica e altos valores de resistência à compressão axial, apresentando picos de thenardita e gipsita pela análise por DRX. A correlação linear $R^{2}$ de 0,85 entre os ensaios demonstrou a sua efetividade na detecção do ataque interno por sulfatos em testemunhos de concreto. Esse trabalho foi desenvolvido no âmbito do Programa de P\&D ANEEL, projeto 6491-0301/2013.

Palavras-chave: ataque interno por sulfatos, ensaios destrutivos, ensaios não destrutivos, concreto compactado a rolo (CCR)

Abstract: The presence of sulfate ions $\left(\mathrm{SO}_{4}^{2-}\right)$ inside the cementitious matrix of concrete can originate a type of internal attack, resulting in its deterioration over time. These ions can react with alkalis of the cement, forming compounds such as gypsum, ettringite and other sulfate salts, with expansive characteristics. This attack can cause new chemical reactions, changing the physical and mechanical properties of concrete structures. Thus, the present work had the objective to evaluate the physical and mechanical behavior of rolled compacted concrete (RCC) cores, extracted from a hydroelectric power plant dam with signs of pathological manifestation of internal sulfate attack. After visual inspection of the structures, there were selected the sites for the extraction of the cores and development the tests of electrical resistivity and axial compressive strength. Different results were obtained in block 22, with low values for electrical resistivity and high values for axial compressive strength, showing thenardite and gypsum peaks by XRD analysis. The linear correlation $R^{2}$ of 0,85 between the tests showed its effectiveness in the detection of the internal sulfate attack in concrete cores. This work was developed under the ANEEL P\&D Program, project 6491-0301/2013.

Keywords: internal sulfate attack, destructive tests, non-destructive tests, rolled compacted concrete (RCC) 


\section{Introdução}

Apesar dos estudos desenvolvidos nos últimos anos, pesquisas e discussões sobre os mecanismos do ataque por sulfatos e seus processos de formação e deterioração em compostos cimentícios são complexos, ainda sem a consolidação dos seus resultados [1-5].

O ataque interno por sulfatos pode ser caracterizado pela ação destrutiva provocada por uma série de reações químicas e físicas, que ocorrem entre os compostos hidratados da pasta de cimento endurecida e os íons sulfatos $\left(\mathrm{SO}_{4}^{2-}\right)$, presentes na solução dos poros da matriz, resultando na formação de produtos que podem levar à expansões e fissuração.

Os íons sulfatos podem estar presentes nos materiais que compõem o concreto, como a água de amassamento, cimentos ou agregados. Estes últimos podem conter sais de sulfatos precipitados em suas superfícies, como os sulfatos de cálcio, ferro, sódio, magnésio, entre outros (Figura 1a). Podem ainda ser compostos com sulfetos minerais, que contém enxofre $(S)$ em sua composição [6] (Figura 1b). Dentre estes minerais, pode-se citar a marcassita, calcopirita, pirrotita e a pirita.
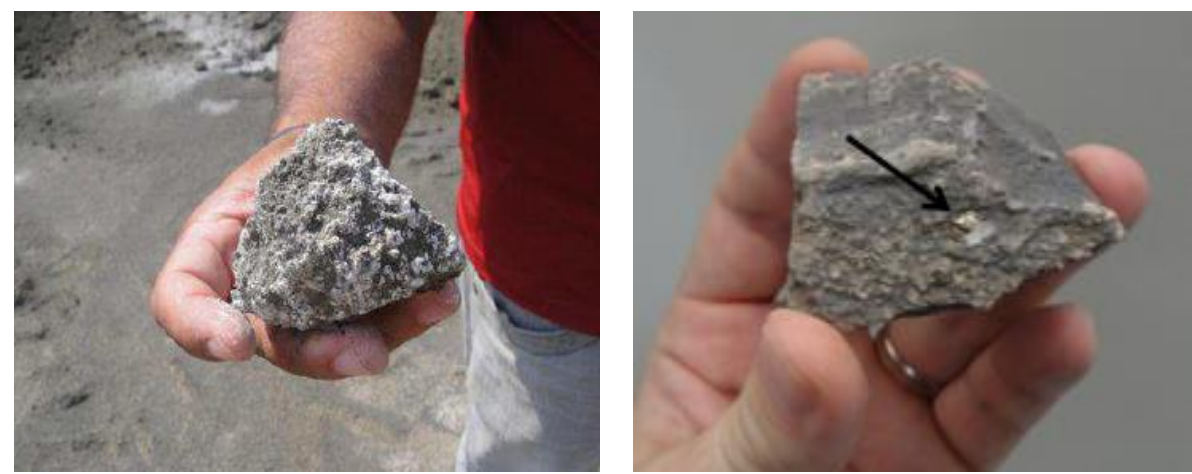

Figura 1: (a) Agregado com precipitação de composto sulfatado [4] e (b) com presença de sulfeto mineral [7].

Obras de grande porte, como as barragens em concreto, são executadas com agregados extraídos e britados a partir de maciços rochosos localizados próximos aos empreendimentos, devido, normalmente, à sua grande distância em relação aos centros fornecedores de insumos. Consequentemente, isto dificulta a criteriosa seleção dos materiais, podendo ocorrer o emprego de agregados potencialmente reativos para os concretos, como aqueles que contém pirita $\left(\mathrm{FeS} \mathrm{S}_{2}\right)$ em sua composição, gerando a fonte interna de íons sulfatos por oxidação ou que contenham sais de sulfatos precipitados em sua superfície [6, 8].

Durante o período construtivo, quando a extração de agregados dos maciços rochosos é intensa, reações de oxidação em locais com sulfetos minerais podem ter início, como nos pontos de interceptação dos planos de xistosidade e fraturas mais abertas. Isto ocorre devido à maior exposição destes sulfetos ao oxigênio e à umidade ambiente, acelerando a sua oxidação e formação de íons sulfato $\left(\mathrm{SO}_{4}^{2-}\right)$ [9].

Nixon (1978) e Bérube e colaboradores (1986), citados por [3], fazem ainda uma observação sobre a precipitação de sulfatos secundários nestes maciços. Segundo os autores, soluções ricas em íons cálcio, ferro e sulfato, podem migrar por 
capilaridade por fissuras e fraturas dos maciços que, sob condições de altas temperaturas e baixa pressão, podem formar cristais secundários, como a gipsita, formando um material pulverulento de cor branca. Características similares de afloramentos em superfícies rochosas também foram verificadas próximas às barragens de Graus e Tavascán, na Espanha, identificando-se compostos como a jarosita, hidróxido de ferro, gipsita e pinguerita [1].

Logo, os agregados extraídos de pedreiras que contém enxofre em sua composição podem apresentar manifestações na fase sulfatada, muito mais solúvel que os sulfetos minerais. Sua presença pode ser verificada com a evaporação da água, provocando a precipitação de sulfatos hidratados na forma de eflorescências brancas superficiais [10].

Um dos produtos formados pela reação química entre os íons sulfatos e os produtos de hidratação do cimento é a gipsita $\left(\mathrm{CaSO}_{4} \cdot 2 \mathrm{H}_{2} \mathrm{O}\right)$, ocorrendo em soluções com altas concentrações destes íons (> $8.000 \mathrm{ppm} \mathrm{SO}_{4}^{2-}$ ). Apesar do seu estudo não ser enfatizado durante o ataque interno por sulfatos, quando há maior atenção para a formação da etringita secundária, a sua presença ou formação na matriz cimentícia endurecida pode causar modificações na sua microestrutura, com enfraquecimento do concreto, formação de microfissuras e expansões.

A formação da gipsita inicia-se com as reações entre os íons sulfatos e o hidróxido de cálcio disponível na pasta de cimento (Equação 1), ocorrendo nos poros do concreto, produzindo um aumento da resistência inicial e densidade do concreto [11].

$$
\underset{\text { (hidróxido de cálcio) }}{\mathrm{Ca}(\mathrm{OH})_{2}}+\underset{\text { (íon sulfato) }}{\mathrm{SO}_{4}^{2-}}+2 \mathrm{H}_{2} \mathrm{O} \rightarrow \underset{\text { (gipsita) }}{\mathrm{CaSO}_{4} \cdot 2 \mathrm{H}_{2} \mathrm{O}}+2 \mathrm{OH}^{-}
$$

Alguns tipos de sais de sulfato, como o sulfato de sódio ou thenardita $\left(\mathrm{Na}_{2} \mathrm{SO}_{4}\right)$, podem dar origem à gipsita, formando-se a partir do hidróxido de cálcio disponível (Equação 2) [12].

$$
\underset{\text { óxido de cálcio })}{\mathrm{Ca}(\mathrm{OH})_{2}}+\underset{\text { (sulfato de sódio) }}{\mathrm{Na}_{2} \mathrm{SO}_{4}}+2 \mathrm{H}_{2} \mathrm{O} \rightarrow \underset{\text { (gipsita) }}{\mathrm{CaSO}_{4} \cdot 2 \mathrm{H}_{2} \mathrm{O}}+2 \mathrm{NaOH}
$$

Devido à maior facilidade para a sua nucleação, a gipsita tende a se formar em fissuras ou poros da pasta de cimento, causando o amolecimento superficial, expansão e lascamento do concreto, resultando na perda de massa da estrutura [13].

Em relação aos cimentos empregados para a produção de concretos sujeitos ao ataque interno por sulfatos, [14] citam que cimentos que geram baixos teores de hidróxido de cálcio durante sua hidratação, como aqueles com pelo menos $25 \%$ de adições pozolânicas, têm melhor eficiência quando submetidos ao ataque de íons sulfatos. Em outros casos, concretos produzidos com cimentos com baixos teores de aluminato tricálcico (menos de $5 \%$, ou até mesmo $0 \%$ ), não proporcionam proteção contra os danos causados por esta manifestação patológica, principalmente em altas concentrações de sulfatos (> $1.500 \mathrm{mg} / \mathrm{L}$ ), indicando que os mecanismos de expansão e fissuração não podem ser atribuídos somente à formação da etringita [14, 15]. 
Sendo o composto mais deletério do ataque por sulfatos, a etringita é um sulfoaluminato cálcico hidratado cristalino $\left(3 \mathrm{CaO} \cdot \mathrm{Al}_{2} \mathrm{O}_{3} 3 \mathrm{CaSO}_{4} \cdot 32 \mathrm{H}_{2} \mathrm{O}\right.$ ou $\left.\mathrm{C}_{6} A \bar{S}_{3} \mathrm{H}_{32}\right)$, podendo formar-se na hidratação normal do cimento Portland e sua presença na pasta endurecida, quando em condições normais de cura e uso, não diminui a durabilidade da estrutura [16].

Assim como a gipsita, sua formação tem início em vazios, poros e fissuras préexistentes na matriz cimentícia, causando tensões internas após o preenchimento completo destes espaços, resultando em novas fissuras e expansões no concreto [17]. A etringita pode formar-se após a ocupação de todo o volume de poros pela gipsita, que tende a reagir com a fase aluminato da pasta de cimento hidratada, conforme Equação 3 [2]

$$
\underset{\text { (gipsita) }}{3 C \bar{S} H}+\begin{gathered}
3 C_{3} A \\
\text { (aluminato tricálcico) }
\end{gathered}+19 \mathrm{H} \rightarrow \begin{gathered}
3 C_{6} A \bar{S}_{3} H_{32} \\
(\text { etringita })
\end{gathered}
$$

A etringita também pode ser resultado da reação entre a gipsita e 0 monossulfoaluminato disponível, conforme a Equação 4 [6, 17, 18].

$$
\underset{\text { (monossulfoaluminato })}{\mathrm{C}_{4} A \bar{S} H_{12}}+\underset{\text { (gipsita) }}{2 C \bar{S} H}+16 H \rightarrow \underset{\text { (etringita) }}{C_{6} A \bar{S}_{3} H_{32}}
$$

Assim, de forma geral, os produtos neoformados tendem, inicialmente, a provocar a colmatação dos poros, densificando a matriz cimentícia e aumentando a resistência à compressão nas primeiras idades. Porém, a longo prazo, com a continuidade das reações de expansão, estas tendem a provocar fissuras, diminuindo a resistência do concreto. Em pesquisa desenvolvida com CCRs submetidos ao ataque por sulfato de sódio $\left(\mathrm{Na}_{2} \mathrm{SO}_{4}\right)$ [19], verificou-se um aumento nas resistências à compressão nas primeiras idades dos corpos de prova durante o período de dormência das expansões. Ao longo do processo, detectou-se uma diminuição nas resistências, devido ao aumento das tensões internas provocadas pelos produtos neoformados.

Em relação ao CCR, este material é formado de uma mistura seca, disposta sobre uma determinada base e compactada como aterro, sendo empregado os mesmos insumos do concreto convencional (CCV) [20]. Segundo os autores, devido à sua rápida execução, o CCR é utilizado para a construção de estradas e barragens, mostrando-se uma opção bastante econômica, com baixo custo de produção e rápida instalação. Para a utilização em barragens, a sua vantagem é a redução na quantidade de cimento, obtendo-se dosagens com valores de até $100 \mathrm{~kg} / \mathrm{m}^{3}$, podendo haver a adição de minerais como as cinzas volantes.

Assim, este trabalho tem como objetivo avaliar o comportamento físico e mecânico de testemunhos de CCR extraídos de uma barragem com sinais de ataque interno por sulfatos. Serão analisados os procedimentos desenvolvidos durante o processo de inspeção visual, com posterior análise dos resultados obtidos em laboratório, através dos ensaios de resistência à compressão axial e resistividade elétrica das regiões selecionadas da barragem. 


\section{Materiais e métodos}

\subsection{Materiais}

O cimento utilizado para a produção do CCR da barragem em estudo foi o CP IV-32, proveniente da região de Rio Branco do Sul, no Paraná. Para este tipo de cimento, conforme a NBR 5737/1992, é permitido um teor de material pozolânico entre $15 \%$ e $50 \%$ em massa de cimento. Os ensaios de caracterização física e mecânica foram realizados conforme a NBR 5736/1991 (Tabela 1 e Tabela 2) e a caracterização química foi realizada por FRX, conforme a NBR 14656/2001 (Tabela 3).

Tabela 1: Resultados dos ensaios físicos - Cimento CP IV - 32 [4]

\begin{tabular}{lccccccc}
\hline & \#200 & \#325 & $\begin{array}{c}\text { Blaine } \\
\left(\mathbf{c m}^{2} / \mathbf{g}\right)\end{array}$ & $\begin{array}{c}\text { Massa } \\
\text { específica } \\
\left(\mathbf{g} / \mathbf{c m}^{3}\right)\end{array}$ & $\begin{array}{c}\text { Início } \\
\text { de } \\
\text { Pega } \\
(\mathbf{m i n})\end{array}$ & $\begin{array}{c}\text { Fim de } \\
\text { Pega } \\
(\mathbf{m i n})\end{array}$ & $\begin{array}{c}\text { Exp. } \\
\text { Quente } \\
\mathbf{( m m})\end{array}$ \\
\hline Resultado & 0,7 & 2,0 & 4710 & 2,88 & $05: 30$ & $06: 15$ & 0,00 \\
\hline $\begin{array}{l}\text { Limite } \\
\text { Normatizado }\end{array}$ & $\begin{array}{c}\text { Máx=8,0 } \\
\%\end{array}$ & - & - & - & Min=1h & Máx. $=12 \mathrm{~h}$ & $\begin{array}{c}\text { Máx. }=5 \\
\mathrm{~mm}\end{array}$ \\
\hline
\end{tabular}

Tabela 2: Resultados dos ensaios mecânicos à compressão - Cimento CP IV - 32 [4]

\begin{tabular}{lccc}
\hline & 3 dias (MPa) & $\mathbf{7}$ dias (MPa) & $\mathbf{2 8}$ dias (MPa) \\
\hline Resultado & 23,2 & 25,2 & 37,5 \\
\hline Limite Normatizado & $\mathrm{Min}=10 \mathrm{MPa}$ & $\mathrm{Min}=20 \mathrm{MPa}$ & $\mathrm{Min}=32 \mathrm{MPa}$ \\
\hline
\end{tabular}

Tabela 3: Resultados dos ensaios químicos por FRX - Cimento CP IV - 32 [4]

\begin{tabular}{|c|c|c|c|c|c|c|c|}
\hline & $\mathrm{SiO}_{2}(\%)$ & $\begin{array}{c}\mathrm{Al}_{2} \mathrm{O}_{3} \\
(\%)\end{array}$ & $\begin{array}{c}\mathrm{Fe}_{2} \mathrm{O}_{3} \\
(\%)\end{array}$ & $\begin{array}{l}\mathrm{CaO} \\
(\%)\end{array}$ & $\mathrm{MgO}(\%)$ & $\begin{array}{l}\mathrm{K}_{2} \mathrm{O} \\
(\%)\end{array}$ & $\begin{array}{c}\mathrm{Na}_{2} \mathrm{O} \\
(\%)\end{array}$ \\
\hline Resultado & 32,92 & 10,81 & 3,15 & 41,16 & 2,96 & 1,33 & 0,30 \\
\hline $\begin{array}{l}\text { Limite } \\
\text { Normatizado }\end{array}$ & - & , & - & - & $<6,5$ & - & - \\
\hline & $\mathrm{P}_{2} \mathrm{O}_{5}(\%)$ & $\begin{array}{l}\mathrm{TiO}_{2} \\
(\%)\end{array}$ & $\begin{array}{c}\text { MnO } \\
(\%)\end{array}$ & $\begin{array}{l}\mathrm{SO}_{3} \\
(\%)\end{array}$ & $\begin{array}{c}\text { CaO Livre } \\
(\%)\end{array}$ & $\begin{array}{l}\text { PF } \\
(\%)\end{array}$ & RI (\%) \\
\hline Resultado & 0,14 & 0,55 & 0,10 & 2,60 & 0,92 & 4,51 & 29,25 \\
\hline $\begin{array}{l}\text { Limite } \\
\text { Normatizado }\end{array}$ & - & - & - & $<4$ & - & $<4,5$ & - \\
\hline
\end{tabular}

Os agregados graúdos e miúdos, do tipo diabásio, são resultantes do processo de britagem de rochas oriundas de uma pedreira localizada próxima à cidade de Telêmaco Borba, no Paraná. Os agregados empregados foram britados nas granulometrias de areia, pedrisco, brita $25 \mathrm{~mm}$ e brita $50 \mathrm{~mm}$. Os ensaios de caracterização física e química foram realizados conforme a NBR 7211/2009 e apresentados os resultados na Tabela 4. 
GOTO, H.; ET AL., AVALIAÇÃO NÃO DESTRUTIVA DO ATAQUE INTERNO POR SULFATOS EM TESTEMUNHOS DE CCR DE UMA BARRAGEM. $2^{\circ}$ Simpósio Paranaense de Patologia das Construções (2 SPPC), artigo 2SPPC1020, pp. 237-252, 2017. DOI:

Tabela 4 - Análise petrográfica do diabásio [4]

\begin{tabular}{|c|c|c|}
\hline & \multicolumn{2}{|c|}{ Características } \\
\hline \multirow{2}{*}{ Tipo de amostra } & Cor & Cinza escuro \\
\hline & Estrutura & Maciça \\
\hline \multirow{7}{*}{$\begin{array}{l}\text { Composição } \\
\text { Mineralógica }\end{array}$} & $\begin{array}{l}\text { Andesina/Labradorita }(\mathrm{Na}, \mathrm{Ca})(\mathrm{Si}, \\
\mathrm{Al})_{4} \mathrm{O}_{8}(\%)\end{array}$ & 55 a 60 \\
\hline & $\begin{array}{l}\text { Augita }(\mathrm{Ca}, \mathrm{Na})(\mathrm{Mg}, \mathrm{Fe}, \mathrm{Al})(\mathrm{Si}, \mathrm{Al})_{2} \mathrm{O}_{6} \\
(\%)\end{array}$ & 30 a 35 \\
\hline & Minerais opacos (\%) & 5 \\
\hline & Apatita $\left(\mathrm{Ca}_{5}\left(\mathrm{PO}_{4}\right)_{3}(\mathrm{~F}, \mathrm{OH}, \mathrm{Cl})(\%)\right.$ & $<1$ \\
\hline & Feldspato alcalino (\%) & $<1$ \\
\hline & Argilomineral (\%) & 1 a 2 \\
\hline & Quartzo microgranular (\%) & $<1$ \\
\hline \multirow{2}{*}{$\begin{array}{l}\text { Classificação da } \\
\text { rocha }\end{array}$} & Tipo de rocha & Ígnea \\
\hline & Nome & Microgabro - diabásio \\
\hline $\begin{array}{l}\text { Reatividade potencial } \\
\text { álcali-agregado }\end{array}$ & Potencial reativo & $\begin{array}{l}\text { Potencialmente } \\
\text { reativo }\end{array}$ \\
\hline
\end{tabular}

Por meio da microscopia ótica de luz refletida, a análise qualitativa resultou na presença dos seguintes sulfetos: pirita $\left(\mathrm{FeS}_{2}\right)$, calcopirita $\left(\mathrm{CuFeS}_{2}\right)$, pirrotita $\left(\mathrm{Fe}_{(1-x)} \mathrm{S}\right)$ e esfarelita (ZnS). Pela análise semiquantitativa por estimativa visual, foram detectados teores de sulfetos inferiores a $0,50 \%$. A caracterização química, realizada por FRX, empregando pastilhas de pó prensados, indicou uma maior quantidade de óxidos de silício e ferro, e teor de 0,30\% de óxidos de enxofre (Tabela 5).

Tabela 5: Análise por fluorescência de raios $X$ [4]

\begin{tabular}{ccccccccccccc}
\hline \multirow{2}{*}{ Amostra } & $\mathrm{SiO}_{2}$ & $\mathrm{Fe}_{2} \mathrm{O}_{3}$ & $\mathrm{Al}_{2} \mathrm{O}_{3}$ & $\mathrm{CaO}$ & $\mathrm{TiO}_{2}$ & $\mathrm{MgO}$ & $\mathrm{Na}_{2} \mathrm{O}$ & $\mathrm{K}_{2} \mathrm{O}$ & $\mathrm{P}_{2} \mathrm{O}_{5}$ & $\mathrm{SO}_{3}$ & P.F. \\
& $(\%)$ & $(\%)$ & $(\%)$ & $(\%)$ & $(\%)$ & $(\%)$ & $(\%)$ & $(\%)$ & $(\%)$ & $(\%)$ & $(\%)$ \\
\hline Agregado & 47,10 & 18,30 & 13,00 & 9,10 & 3,20 & 2,80 & 2,50 & 1,50 & 0,80 & 0,30 & 0,81 \\
\hline
\end{tabular}

Por meio de um ensaio de oxidação com os agregados citados, realizando-se medições de $\mathrm{pH}$, total de sólidos dissolvidos e condutividade elétrica, confirmou-se, pelo teste $F(A N O V A$ ) a um nível de significância de $5 \%$, o teor aproximado de $0,50 \%$ de sulfetos minerais presentes nos agregados, corroborando os ensaios citados anteriormente [7].

A água de amassamento é proveniente do rio Tibagi, na região situada entre as cidades de Telêmaco Borba e Ortigueira. Os ensaios de caracterização físico-química foram realizados conforme a NBR 15900/2009 e NM 137, não apresentando valores acima dos limites preconizados pelas normas (Tabela 6).

Tabela 6: Análise química da água de amassamento [4]

\begin{tabular}{|c|c|c|c|}
\hline & \multicolumn{2}{|c|}{ Valores Limites } & \multirow{2}{*}{ Resultado } \\
\hline & NM 137 & NBR 15900 & \\
\hline Teor de sólidos (mg/L) & $<5.000$ & $<50.000$ & 69 \\
\hline Matéria orgânica (mg/L) & - & & 26 \\
\hline Sulfatos (mg/L) & $<2.000$ & $<2.000$ & 13,6 \\
\hline $\mathrm{pH}$ & 5,5 a 9,0 & $\geq 5,5$ & 6,2 \\
\hline Cloretos (mg/L) & $<700$ & $<1.000$ & 3,3 \\
\hline
\end{tabular}


Durante as etapas de concretagem, foram produzidas 3 dosagens de CCR, denominadas de CCR 02, CCR 03 e CCR 04. As dosagens CCR 02 e 03 foram executadas na região da margem direita, compreendendo os blocos 3 a 16, enquanto na margem esquerda foi executado o CCR 04, compreendendo os blocos 17 a 41 (Figura 2).

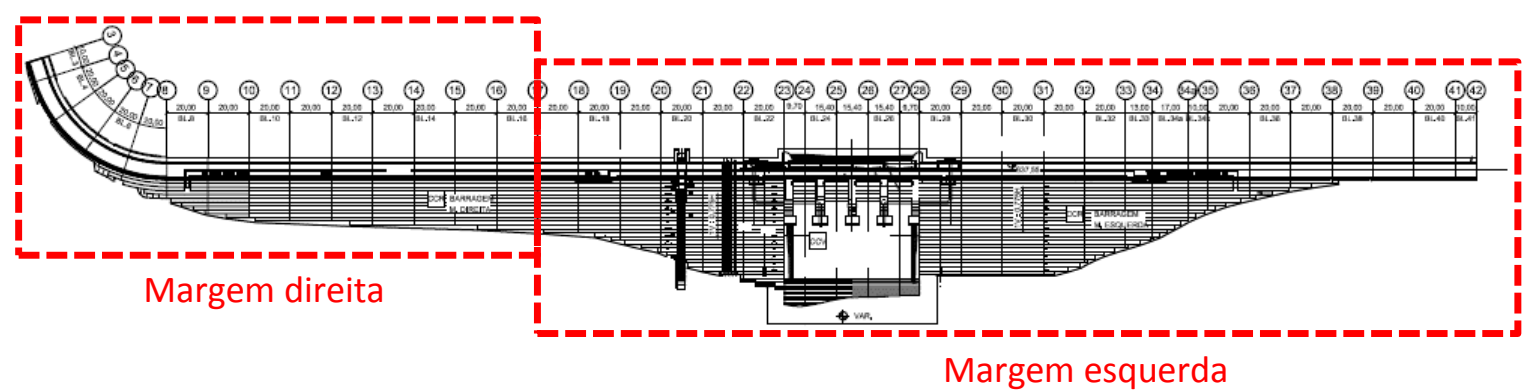

Figura 2: Planta baixa da barragem - detalhe das margens direita e esquerda.

Durante o período construtivo, após a detecção da baixa evolução das resistências à compressão dos corpos de prova das dosagens CCR 02 e 03, com consumo de cimento de 80 e $75 \mathrm{~kg} / \mathrm{m}^{3}$, respectivamente, adotou-se a dosagem CCR 04, com maior consumo de cimento $\left(85 \mathrm{~kg} / \mathrm{m}^{3}\right)$ [4], conforme descritos na

Tabela 7. De acordo com os volumes executados, verificou-se que as dosagens CCR 02 e CCR 03 representam, juntas, cerca de $18 \%$ do volume total de concreto da barragem, enquanto a dosagem CCR 04 representa $82 \%$.

Tabela 7 - Dosagem dos CCRs utilizados para a execução da barragem.

\begin{tabular}{ccccc}
\hline \multirow{2}{*}{ Descrição } & \multirow{2}{*}{ Unidade } & \multicolumn{3}{c}{ Dosagem } \\
\cline { 3 - 5 } & & CCR 02 & CCR 03 & CCR 04 \\
\hline Fck especificado $_{\text {Idade }}$ & dias & 7 & 7 & 7 \\
\hline Cimento & $\mathrm{kg} / \mathrm{m}^{3}$ & 80 & 180 & 180 \\
\hline Água & $\mathrm{kg} / \mathrm{m}^{3}$ & 135 & 125 & 125 \\
\hline Areia artificial & $\mathrm{kg} / \mathrm{m}^{3}$ & 1.254 & 1.272 & 1.271 \\
\hline Brita $25 \mathrm{~mm}$ & $\mathrm{~kg} / \mathrm{m}^{3}$ & 733 & 619 & 614 \\
\hline Brita $50 \mathrm{~mm}$ & $\mathrm{~kg} / \mathrm{m}^{3}$ & 489 & 619 & 614 \\
\hline Fator a/c & $\mathrm{kg} / \mathrm{m}^{3}$ & 1,69 & 1,67 & 1,47 \\
\hline Aditivo plastificante retardador de pega & $\mathrm{kg} / \mathrm{m}^{3}$ & 0,96 & 0,90 & 1,02 \\
\hline Diâmetro máximo & $\mathrm{mm}$ & 50 & 50 & 50 \\
\hline Volume executado $\left(\mathrm{m}^{3}\right)$ & $\mathrm{m}^{3}$ & 36.084 & 79.231 & 519.685 \\
\hline & & & &
\end{tabular}

\subsection{Metodologia}

Previamente à extração dos testemunhos, efetuou-se a inspeção visual em campo, que consistiu no exame da superfície do concreto no interior das galerias de drenagem superior e inferior da barragem, bem como da sua face de jusante. $O$ objetivo foi a detecção de eventuais manifestações do ataque interno por sulfatos, como a alteração de sulfetos e precipitação de sais de sulfatos, sob a forma de fissuras, manchas de ferrugem e materiais esbranquiçados. 
Os locais que apresentaram estes tipos de manifestações foram identificados em projeto, coletando-se amostras dos materiais para análise por DRX, de forma a auxiliar na delimitação dos pontos para extração dos testemunhos.

As perfurações foram realizadas de acordo com a NBR 7680/2007, adotando-se o diâmetro de $150 \mathrm{~mm}$, conforme recomendação da mesma NBR, devendo ser maior do que três vezes a dimensão máxima característica dos agregados.

A extração dos testemunhos da barragem foi realizada com uma sonda rotativa da marca HILTI, modelo DD350 com sistema de arrefecimento hidráulico do cálice de extração. A coroa diamantada utilizada possui dimensões internas livres de $152 \mathrm{~mm}$ de diâmetro e $600 \mathrm{~mm}$ de comprimento. As extrações foram realizadas com o cuidado necessário para que os testemunhos não fossem danificados, condicionando-os em caixas de madeira, evitando impactos ou ações deletérias que comprometessem a sua integridade (Figura 3).
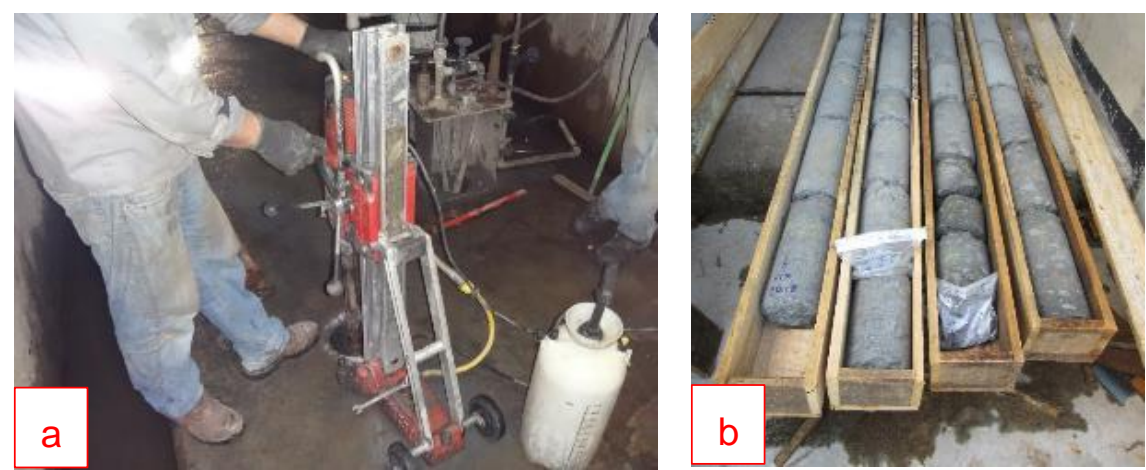

Figura 3: (a) Detalhe da extração dos testemunhos no interior da galeria de drenagem da barragem, com posterior acondicionamento em caixas de madeira (b).

Antes do preparo dos testemunhos, realizou-se a inspeção visual preliminar, com o objetivo de identificar e selecionar as seções adequadas para a realização dos ensaios de resistividade elétrica e compressão axial, buscando a caracterização da massa de concreto. Na sequência, efetuou-se os cortes dos testemunhos com disco diamantado para a configuração dos corpos de prova.

Os ensaios de resistividade elétrica seguiram os procedimentos descritos na ASTM C1760/2012. Foram utilizados 13, 19, 19 e 12 testemunhos extraídos dos blocos 20, 21,22 e 35 respectivamente, executando-se os ensaios em equipamento Sonda Wenner, modelo Resipod da marca Proceq.

Os ensaios de resistência à compressão axial seguiram os procedimentos descritos na NBR 5739/2007, utilizando os testemunhos cilíndricos de $(150 \times 300) \mathrm{mm}$, mantendo a relação diâmetro (d)/altura (h) de 2,0 para a utilização do fator 1,0 de correção. Foram utilizados 10, 14, 12 e 7 testemunhos extraídos dos blocos 20, 21, 22 e 35 respectivamente, executando-se os ensaios em equipamento da marca EMIC, Modelo PC 200 para 200 tf.

\section{Resultados e discussões}

Nas inspeções em campo, realizadas nas galerias de drenagem da barragem de CCR, foram identificados pontos com precipitação de material esbranquiçado nas 
regiões dos blocos 8, 9, 11, 12, 18 a 27, 29 a 32 e 34 a 35, com maior intensidade entre os blocos 19 a 22. Os principais pontos detectados foram as juntas de contração entre blocos, onde o acabamento final do CCR foi realizado na superfície das paredes, entre as peças pré-moldadas de concreto convencional (CCV) (Figura 4a). A análise por DRX, realizada com material coletado na junta de contração 22, entre os blocos 21 e 22, permitiu a identificação de picos das fases cristalinas thenardita e gipsita (Figura 4b).
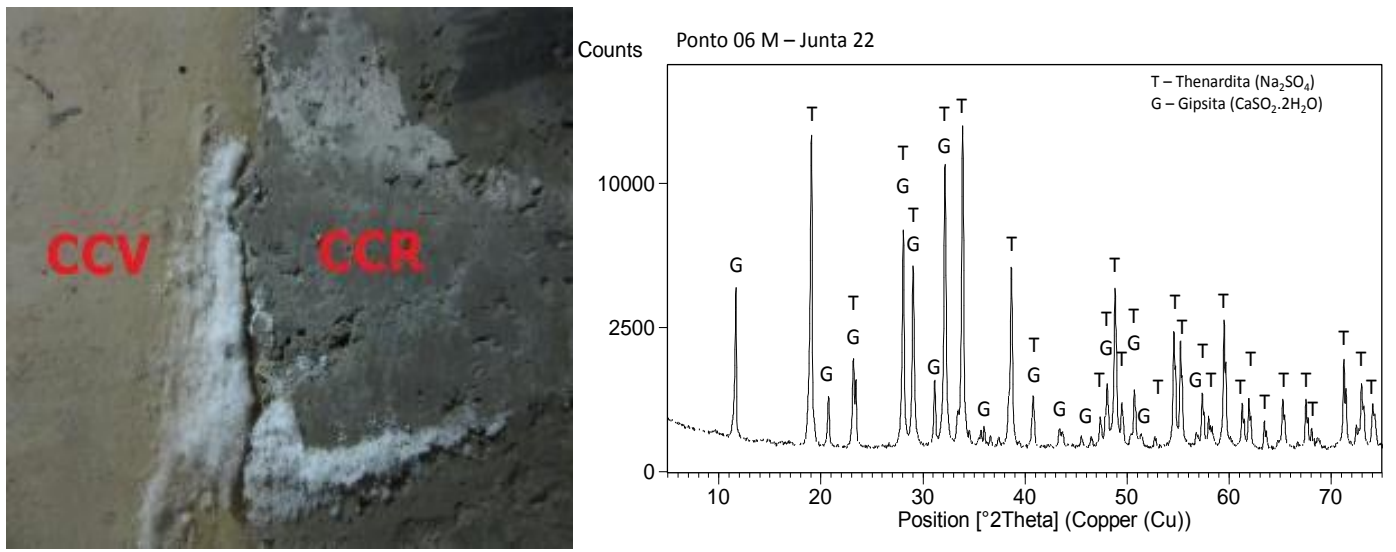

Figura 4: a) Junta de contração 22 no interior da galeria de drenagem. b) Difratograma do material branco coletado identificando picos de thenardita e gipsita.

Posteriormente, definiu-se como locais de extração dos testemunhos, os blocos 20 , 21, 22 e 35, buscando analisar as regiões mais afetadas.

Os resultados dos ensaios de resistência à compressão axial dos testemunhos extraídos estão apresentados na Tabela 8 e Figura 5, com seus respectivos valores médios, desvios-padrões (DP) e coeficientes de variação (CV).

Tabela 8 - Valores médios, desvios-padrões (DP) e coeficientes de variação (CV) para os resultados de resistência à compressão axial dos blocos 20, 21, 22 e 35

\begin{tabular}{c|c|c|c|c}
\hline & BL. 20 & BL. 21 & BL. 22 & BL. 35 \\
\hline Número de Amostras & 10 & 14 & 12 & 7 \\
\hline Média (MPa) & 12,51 & 12,56 & 12,98 & 10,60 \\
\hline DP & 2,40 & 2,46 & 6,46 & 2,07 \\
\hline CV (\%) & $19,18 \%$ & $19,59 \%$ & $49,79 \%$ & $19,56 \%$ \\
\hline
\end{tabular}




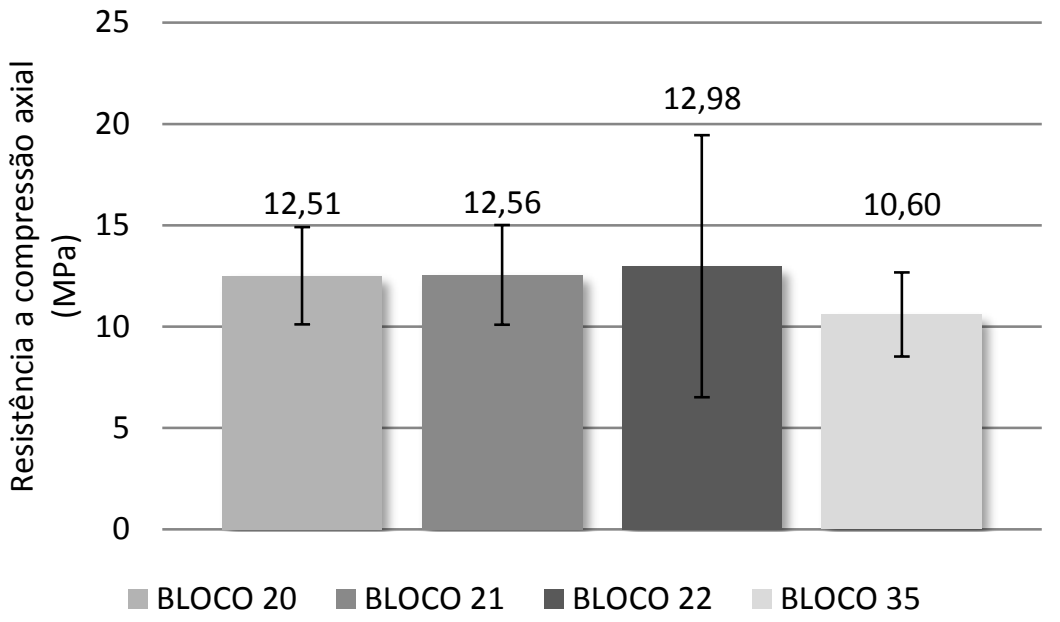

Figura 5: Valores médios dos resultados dos ensaios de resistência à compressão axial para os blocos 20, 21, 22 e 35

Os resultados das resistências médias à compressão axial para os blocos 20, 21 e 22 apresentaram valores próximos entre si, com valor médio menor para o bloco 35 , porém não havendo diferença estatística em relação aos demais blocos. Aos resultados obtidos ainda devem ser considerados os efeitos de traumatismo gerado durante o processo de extração dos testemunhos. Este processo pode causar um pré-fissuramento dos testemunhos de CCR, podendo provocar a diminuição da resistência à compressão da ordem de $30 \%$ em relação a corpos de prova moldados em laboratório [21].

Em relação aos coeficientes de variação, os valores obtidos para os blocos 20, 21 e 35 encontram-se no intervalo dos valores médios relatados em outros trabalhos desenvolvidos, com CV $=19,66 \%$ [21] e CV $=19,60 \%$ [22]. Já para o bloco 22, verificou-se uma maior dispersão nos resultados obtidos, atingindo um CV de 49,79\%, indicando diferenças na sua estrutura em relação às demais perfurações de testemunhos.

Conforme o difratograma apresentado na Figura $4 \mathrm{~b}$, a presença dos compostos thenardita $\left(\mathrm{Na}_{2} \mathrm{SO}_{4}\right)$ e gipsita $\left(\mathrm{CaSO}_{4} \cdot 2 \mathrm{H}_{2} \mathrm{O}\right)$ podem provocar a colmatação dos poros da matriz cimentícia, resultando no aumento das resistências à compressão na região do bloco 22, que apresentou a maior média dos resultados em relação aos demais blocos. Resultados similares também foram verificados em trabalhos correlatos [11, 19].

A colmatação inicial dos poros, com posterior evolução do crescimento dos cristais de sulfatos, provocando expansão e fissuração da matriz cimentícia, pode resultar em reduções futuras nas resistências à compressão do CCR analisado. Em pesquisa desenvolvida com corpos de prova de CCR [20], verificou-se que a imersão em solução de sulfato de sódio a $5 \%$ por cerca de 1 ano, provocou aumento de quase $200 \%$ nos resultados de expansão deste material. Assim, o grau de compactação de $99,0 \%$ adotado para a produção do CCR, que pode proporcionar valores de permeabilidade próximos aos dos CCVs, não retarda a ocorrência de expansões adicionais durante $\mathrm{o}$ ataque interno por sulfatos. 
Para a resistividade elétrica, os resultados estão apresentados na Tabela 9 e na Figura 6, com seus respectivos valores médios, desvios-padrões (DP) e coeficientes de variação $(\mathrm{CV})$ dos valores obtidos nos ensaios.

Tabela 9 - Valores médios, desvios-padrões (DP) e coeficientes de variação (CV) para as leituras de resistividade elétrica dos testemunhos dos blocos 20, 21, 22 e 35

\begin{tabular}{c|c|c|c|c}
\hline & BL. 20 & BL. 21 & BL. 22 & BL. 35 \\
\hline Número de amostras & 13 & 19 & 19 & 12 \\
\hline Média (k囚.cm) & 53,51 & 54,30 & 44,82 & 46,26 \\
\hline DP & 12,07 & 16,91 & 17,06 & 11,78 \\
\hline CV (\%) & $22,56 \%$ & $31,14 \%$ & $38,07 \%$ & $25,47 \%$ \\
\hline
\end{tabular}

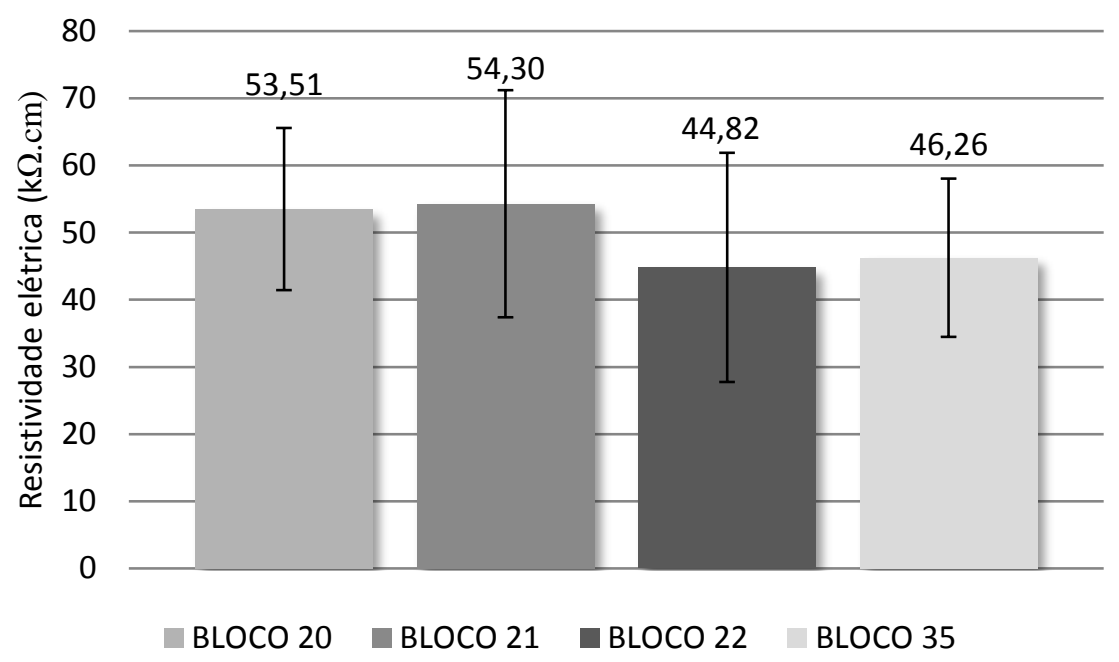

Figura 6 - Valores médios das leituras de resistividade elétrica para os blocos 20 , 21,22 e 35

As médias das leituras de resistividade elétrica entre os blocos tenderam à valores menores para o bloco 22, sugerindo a maior condutividade elétrica nesta região. Isto pode ser consequência da presença de íons dissolvidos na água presente nos poros do concreto, como os íons sulfatos $\left(\mathrm{SO}_{4}^{2-}\right)$. A influência na resistividade elétrica em corpos de prova de concreto foi verificada por [23], constatando que para um teor de umidade de $1,5 \%$, a resistividade elétrica diminuiu de 40 para $10 \mathrm{k} \Omega . \mathrm{cm}$, com 0 aumento na concentração de sulfatos de 7,2 para $43,2 \mathrm{~kg} / \mathrm{m}^{3}$. Os autores ainda verificaram que a variação do teor de umidade é pouco significativa quando a concentração de sais é elevada. Baixos valores de resistividade elétrica também podem estar relacionados com poros de grandes dimensões e com altos teores de umidade, uma vez que a corrente elétrica é transmitida pelos íons presentes nos líquidos destes poros [24].

A maior condutividade elétrica na região do bloco 22 indica ainda a ocorrência de uma maior interconexão entre os poros do CCR ou maior quantidade de microfissuras formadas ao longo dos anos, gerando maior transporte iônico neste local. 
Assim como nos demais ensaios apresentados, os resultados dos testemunhos extraídos do bloco 22 apresentaram a maior variabilidade, com CV =38,07\%.

Visando analisar o bloco 22, que apresentou maior variabilidade (CV) nos resultados, na Figura 7 está apresentada a correlação entre os ensaios de resistividade elétrica e de compressão axial.

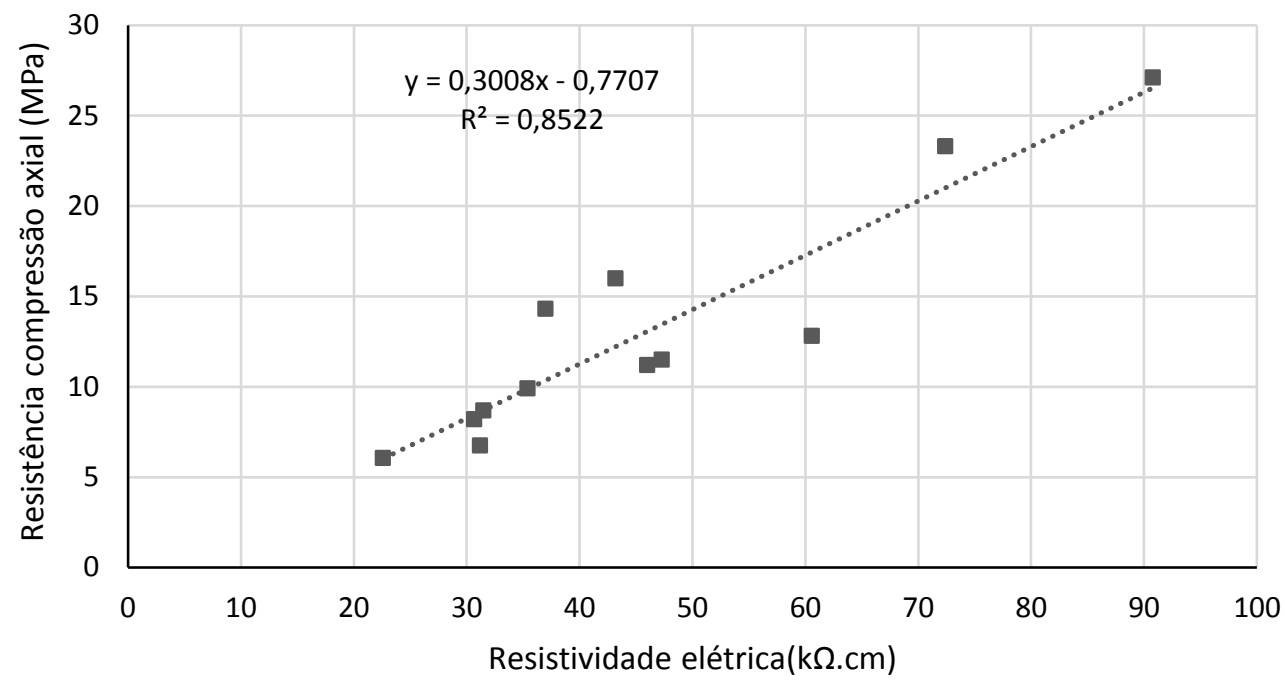

Figura 7: Bloco 22 - Correlação entre as medidas de resistividade elétrica e resistência a compressão axial dos testemunhos

O valor $R^{2}=0,85$ obtido, mostra uma boa correlação entre os resultados dos ensaios, indicando ser adequada a utilização de ensaios de resistividade elétrica e compressão axial para a verificação da deterioração em testemunhos de concreto devido à presença de íons sulfatos.

A extração de testemunhos efetuada no bloco 22 foi realizada até a profundidade de aproximadamente $12,00 \mathrm{~m}$, iniciado a partir da cota do piso da galeria de drenagem inferior da barragem, na cota $571,70 \mathrm{~m}$. Ao longo da profundidade, verifica-se a variabilidade nos resultados de ambos os ensaios, conforme obtido nos CVs da Tabela 8 e Tabela 9 (Figura 8) 


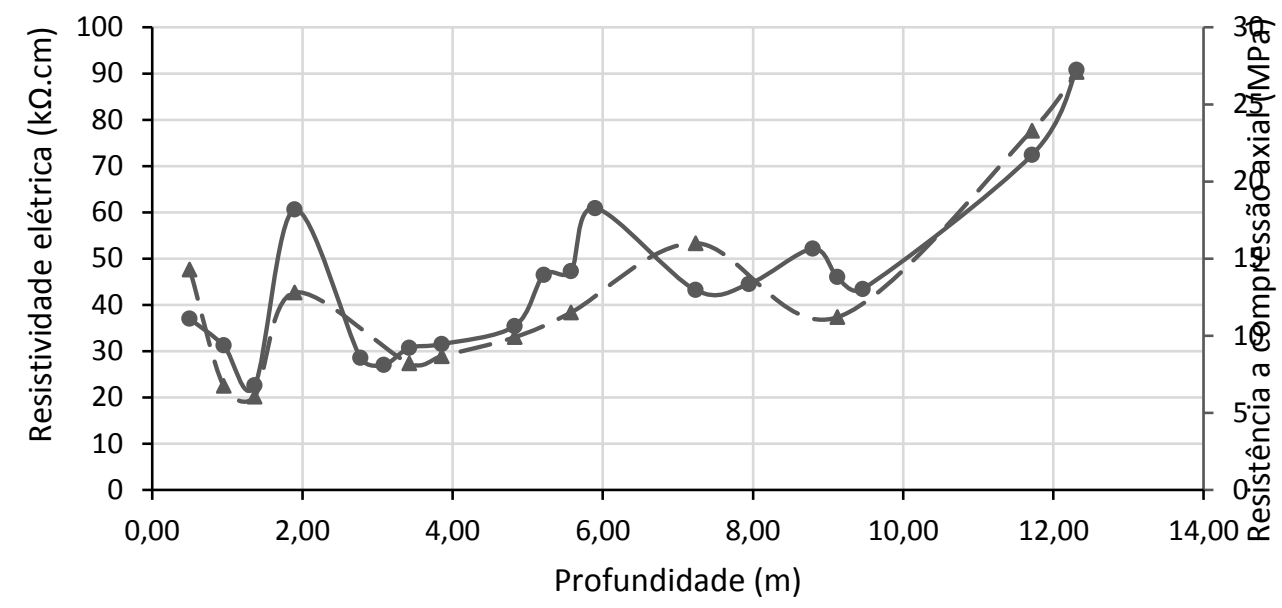

$\longrightarrow$ Resistividade $(\mathrm{k} \Omega \mathrm{cm}) \quad \longrightarrow$ Resistência à compressão (MPa)

Figura 8: Desenvolvimento das propriedades de resistividade elétrica e resistência a compressão axial dos testemunhos extraídos no bloco 22, ao longo da profundidade.

Tal variabilidade nos testemunhos pode ser explicada pelos pontos de maior ou menor intensidade do ataque interno pelos íons sulfatos, que alteram os produtos formados durante as reações de hidratação do cimento Portland.

Nas profundidades aproximadas de 1,37 m e de 2,78 a 4,83 m, constataram-se os menores valores de resistividade elétrica, indicando a maior presença de íons sulfatos dissolvidos na solução dos poros do concreto. Outro indicativo é a possível redução na formação de silicatos de cálcio hidratado $(C S H)$ nas reações de hidratação do cimento, devido ao consumo da portlandita disponível pelos íons sulfatos, que resultaria no menor refinamento dos poros. Isto levaria à formação de poros maiores e interconectados, refletindo nos menores valores de resistência à compressão axial para estes intervalos de profundidade.

\section{Conclusões}

O ataque interno por sulfatos ao concreto é resultado de uma série de reações químicas, que têm início na sua microestrutura, com consequências macroestruturais, afetando suas propriedades físicas e mecânicas, como em barragens de usinas hidrelétricas.

A inspeção visual, com posterior confirmação por DRX da presença de sais de sulfato (thenardita e gipsita) em amostra coletada no bloco 22, mostraram-se eficazes para a investigação preliminar de estruturas com suspeitas de ataque interno por sulfatos, direcionando as investigações posteriores com extração de testemunhos.

Os resultados médios de resistência à compressão entre os blocos analisados demonstraram os possíveis efeitos de colmatação de poros do CCR, provocados pela cristalização dos sais de sulfatos, que ainda podem estar em processo de formação. Isto pode ser evidenciado no bloco 22, que apresentou o maior valor médio de 
resistência a compressão, confirmando a influência macroestrutural dos compostos cristalinos thenardita e gipsita, detectados por DRX da amostra de material esbranquiçado coletado no mesmo bloco.

A presença dos íons sulfatos nas soluções dos poros do CCR, na forma de thenardita e gipsita, pode ainda ser ratificada pelos resultados obtidos nos ensaios de resistividade elétrica. Assim como na resistência à compressão axial, os resultados diferiram para o bloco 22, que apresentou os menores valores de resistividade elétrica, indicando, portanto, sua maior condutividade elétrica, provocada pela presença dos íons sulfatos em solução nesta região.

A maior dispersão obtida nos coeficientes de variação dos ensaios para o bloco 22, quando comparados com resultados obtidos nos demais blocos e com a literatura, também contribuíram para confirmar os efeitos deletérios do ataque por sulfatos ao longo da profundidade da extração.

$O$ valor $R^{2}$ de 0,85 entre os ensaios desenvolvidos com os testemunhos, indicam a boa correlação estatística, mesmo com altos valores de $\mathrm{CV}$, demonstrando sua efetividade na investigação do ataque interno por sulfatos em CCRs.

\section{Agradecimentos}

Os autores agradecem à infraestrutura e ao apoio em recursos humanos e financiamento à COPEL GeT projeto P\&D 6491-0301/2013, à ANEEL, à Coordenação de Aperfeiçoamento de Pessoal de Nível Superior (CAPES), à Fundação Araucária, aos Institutos LACTEC, ao CNPq Lei 8010/90 (LI 15/2187214-1; LI 14/46958145; LI14/3410726-9) e a Universidade Federal do Paraná - PPGECC/UFPR.

\section{Referências}

[1] AYORA, C.; CHINCHÓN, S.; AGUADO, A.; GUIRADO, F. Weathering of iron sulfides and concrete alteration: thermodynamic model and observation in dams from Central Pyrenees, Spain. Cement and Concrete Research, v. 28, n.9, p.1223-1235, 1998.

[2] ARAÚJO, G.S.; CHINCHÓN, S.; AGUADO, A. Evaluation of the behavior of concrete gravity dams suffering from internal sufalte attack. Ibracon Structures and Materials Journal, v.1, n.1, p.84-112, 2008.

[3] GOMIDES, M.J. Investigação de agregados contendo sulfetos e seus efeitos sobre a durabilidade do concreto. Tese (Doutorado - Programa de Pós-Graduação em Engenharia Civil. Universidade Federal do Rio Grande do Sul). Porto Alegre, 2009.

[4] OLIVEIRA, I.C. Análise de dados para elaboração de diretrizes visando à detecção de sulfetos e sulfatos na composição do CCR. Dissertação (Mestrado - Programa de Pós-Graduação em Engenharia de Construção Civil). Universidade Federal do Paraná. Curitiba, 2013. 
[5] CAMPOS, A.; LÓPEZ, C.M.; AGUADO, A. Diffusion-reaction model for the internal sulfate attack in concrete. Construction and Building Materials, n.102, p.531-540, 2015.

[6] SKALNY, J.; MARCHAND, J.; ODLER, I. Sulfate Attack on Concrete. $2^{\circ}$ Ed. Spon Press, London, 2002.

[7] GOTO, H.; BRAGA, V.S.; CAPRARO, A.P.B.; MEDEIROS, M.H.F.; BRAGANÇA, M.O.G.P.; PORTELLA, K.F.; OLIVEIRA, I.C. Physicochemical evaluation of oxidation of diabase aggregates with sulfide minerals: influence of particle size, $\mathrm{pH}$ of the médium and pyrite concentration. Journal of Building Pathology and Rehabilitation, n. 1, Out, 2016.

[8] CAMPOS, A. Análisis numérico de presas de hormigón bajo acciones expansivas. Tesis (Doctoral), Universitat Politècnica de Catalunya, Departament d’Enginyeria de la Construcció, Barcelona, 2012.

[9] BRE SPECIAL DIGEST 1. Concrete in agressive ground. Building Research Establishment Construction Division. United Kingdom, 2005.

[10] CHINCHÓN, J.S.; AYORA, C.; AGUADO, A.; GUIRADO, F. Influence of weathering of iron sulfides contained in aggregates on concrete durability. Cement and concrete research, v. 25, n.6, p.1264-1272, 1995.

[11] CZEREWKO, M.A.; CRIPPS, J.C.; REID, J.M.; DUFFELL, C.G. Sulfur species in geological materials - sources and quantification. Cement and Concrete Composites, v. 25, p. 657-671, 2003.

[12] HIME, W.G.; MATHER, B. "Sulfate attack," or is it?. Cement and Concrete Research, v. 29, p. 789-791, 1999.

[13] SANTHANAM, M.; COHEN, M.D.; OLEK, J. Sulfate attack research - whither now?. Cement and Concrete Research, n.31, p.845-851, Mar 2001.

[14] MEHTA, P.K.; MONTEIRO, P.J.M. Concreto - Estrutura, Propriedades e Materiais. 3ª Ed., Ed. Pini. São Paulo, 2008.

[15] TIAN, B.; COHEN, M.D. Does gypsum formation during sulfate attack on concrete lead to expansion? Cement and concrete research, n. 30, p. 117-123, 2000.

[16] SKALNY, J.; JOHANSEN, V.; THAULOW, N.; PALOMO, A. DEF: Una forma de ataque por sulfatos. Materiales de Construcción, v.46, n.244, 1996.

[17] CHINCHÓN-PAYÁ, S.; AGUADO, A.; CHINCHÓN, S. A comparative investigation of the degradation of pyrite and pyrrhotite under simulated laboratory conditions. Engineering Geology, n. 127, p. 75-80, Dez 2011.

[18] RODRIGUES, A.; DUCHESNE, J.; FOURNIER, B.; DURAND, B.; RIVARD, P.; SHEHATA, M. Mineralogical and chemical assessment of concrete damaged by the oxidation of sulfide-bearing aggregates: Importance of thaumasite formation on reaction mechanisms. Cement and Concrete Research, n. 42, p. 13361347, Jun 2012.

[19] GOMIDES, M.J.; CARASEK, H.; CASCUDO, O. Ataque por sulfatos ao concreto compactado com rolo (CCR). 44ํ Congresso Brasileiro do Concreto Ibracon, Belo Horizonte, 16p., 2002. 
[20] DEBIEB, F.; COURARD, L.; KENAI, S.; DEGEIMBRE, R. Roller compacted concrete with contaminated recycled aggregates. Construction and Building Materials, v. 23, p. 3382-3387, 2009.

[21] MARQUES FILHO, J.; TRABOULSI, M.A.; PAULON, V.A. Estudo de traumatismos em testemunhos de CCR. Revista Espaço Energia, n.1, Out 2004.

[22] TRABOULSI, M.A. Análise do comportamento de juntas de CCR com alto teor de finos. Dissertação (Mestrado - Programa de Pós-Graduação em Engenharia Civil). Universidade Federal do Rio Grande do Sul. Porto Alegre, 2007.

[23] SALEEM, M.; SHAMEEM, M.; HUSSAIN, S.E.; MASLEHUDDIN, M. Effect of moisture, chloride and sulphate contamination on the electrical resistivity of Portland cement concrete. Construction and Building Materials, n. 3, p. 209214, Out 1996.

[24] FERREIRA, R.M.; JALALI, S. NDT measurements for the prediction of 28-day compressive strength. NDT\&E International, n. 43, p. 55-61, 2010. 